OPEN ACCESS

Edited by: Alberto A. Rasia-Filho, Federal University of Health Sciences of Porto Alegre, Brazil

Reviewed by: Dominique Debanne, INSERM U1072 Neurobiologie des canaux loniques et de la Synapse,

France Werner Killb, Johannes Gutenberg-Universität Mainz, Germany

*Correspondence: Karin R. Aubrey karin.aubrey@sydney.edu.au orcid.org/0000-0002-1808-4041

Stéphane Supplisson

stephane.supplisson@ens.fr orcid.org/0000-0002-0062-9752

Received: 02 August 2018 Accepted: 12 October 2018 Published: 06 November 2018

Citation:

Aubrey KR and Supplisson S (2018) Heterogeneous Signaling at GABA and Glycine Co-releasing Terminals.

Front. Synaptic Neurosci. 10:40. doi: 10.3389/fnsyn.2018.00040

\section{Heterogeneous Signaling at GABA and Glycine Co-releasing Terminals}

\author{
Karin R. Aubrey ${ }^{1,2,3 *}$ and Stéphane Supplisson ${ }^{1 *}$ \\ ${ }^{1}$ Institut de Biologie de l'Ecole Normale Supérieure (IBENS), Ecole Normale Supérieure, CNRS, INSERM, PSL Université \\ Paris, Paris, France, ${ }^{2}$ Neurobiology of Pain Laboratory, Kolling Institute, Royal North Shore Hospital, St. Leonards, NSW, \\ Australia, ${ }^{3}$ Pain Management Research Institute, Faculty of Medicine and Health, University of Sydney-Northern Clinical \\ School, St. Leonards, NSW, Australia
}

The corelease of several neurotransmitters from a single synaptic vesicle has been observed at many central synapses. Nevertheless, the signaling synergy offered by cotransmission and the mechanisms that maintain the optimal release and detection of neurotransmitters at mixed synapses remain poorly understood, thus limiting our ability to interpret changes in synaptic signaling and identify molecules important for plasticity. In the brainstem and spinal cord, GABA and glycine cotransmission is facilitated by a shared vesicular transporter VIAAT (also named VGAT), and occurs at many immature inhibitory synapses. As sensory and motor networks mature, GABA/glycine cotransmission is generally replaced by either pure glycinergic or GABAergic transmission, and the functional role for the continued corelease of GABA and glycine is unclear. Whether or not, and how, the GABA/glycine content is balanced in VIAAT-expressing vesicles from the same terminal, and how loading variability effects the strength of inhibitory transmission is not known. Here, we use a combination of loose-patch (LP) and whole-cell (WC) electrophysiology in cultured spinal neurons of GlyT2:eGFP mice to sample miniature inhibitory post synaptic currents (mIPSCs) that originate from individual GABA/glycine co-releasing synapses and develop a modeling approach to illustrate the gradual change in mIPSC phenotypes as glycine replaces GABA in vesicles. As a consistent GABA/glycine balance is predicted if VIAAT has access to both amino-acids, we test whether vesicle exocytosis from a single terminal evokes a homogeneous population of mixed mIPSCs. We recorded mIPSCs from 18 individual synapses and detected glycine-only mIPSCs in 4/18 synapses sampled. The rest (14/18) were co-releasing synapses that had a significant proportion of mixed GABA/glycine mIPSCs with a characteristic biphasic decay. The majority (9/14) of co-releasing synapses did not have a homogenous phenotype, but instead signaled with a combination of mixed and pure mIPSCs, suggesting that there is variability in the loading and/or storage of GABA and glycine at the level of individual vesicles. Our modeling predicts that when glycine replaces GABA in synaptic vesicles, the redistribution between the peak amplitude and charge transfer of mIPSCs acts to maintain the strength of inhibition while increasing the temporal precision of signaling.

Keywords: GABA, glycine, inhibitory neurotransmission, VIAAT, VGAT, GlyT2-eGFP mouse, cotransmission, quantal release 


\section{INTRODUCTION}

A well-established and long accepted postulate known as "Dale's principle" proposes that neurons have chemical unity for signaling (Strata and Harvey, 1999; Tritsch et al., 2016) - meaning that they communicate by releasing the same neurotransmitter at all their synapses. When the quantal nature of synaptic transmission was later discovered, application of Dale's principle implied that each presynaptic terminal shares the particular set of enzymes and transporters that are required for the synthesis, recapture and accumulation of a specific neurotransmitter(s) into the synaptic vesicles, which are recycled and refilled locally before being reused (Hnasko and Edwards, 2012). Now it is clear that many central synapses corelease multiple neurotransmitters, expanding the repertoire of chemical signaling (Vaaga et al., 2014; Granger et al., 2017) and the extent of presynaptic coordination require to uphold Dale's principal.

In the hindbrain, GABA and glycine are coreleased from single vesicles (Jonas et al., 1998; Lu et al., 2008). Although GABA and glycine have separate presynaptic supply mechanisms, postsynaptic receptors, and modulators, they share the same vesicular transporter, VIAAT (Wojcik et al., 2006; Aubrey et al., 2007) and when GABA/glycine are coreleased from the same single vesicle, mixed miniature inhibitory postsynaptic currents (mIPSCs) have a characteristic biphasic time course (Jonas et al., 1998; Keller et al., 2001; Russier et al., 2002). The regulation of GABA/glycine corelease is known to play a significant role during the maturation of spinal inhibitory circuits (Chéry and de Koninck, 1999; Keller et al., 2001; Russier et al., 2002; Coull et al., 2003; Rahman et al., 2013; Medelin et al., 2016), as well as in other hind-brain regions including the auditory nucleus (Kotak et al., 1998; Lu et al., 2008; Fischl and Burger, 2014; Nerlich et al., 2014) and cerebellum (Dugué et al., 2005; Rousseau et al., 2012). Early biochemical examinations of GABA and glycine uptake into synaptosomes (an isolated synaptic terminal preparation) indicated that both amino acids compete for the same vesicular transporter (Fykse and Fonnum, 1988; Burger et al., 1991; Christensen and Fonnum, 1991). This idea was endorsed when VIAAT was found in both GABAergic and glycinergic terminals (McIntire et al., 1997; Sagné et al., 1997) and taken together, these data suggested that the vesicular content is determined by the relative occupancy of GABA/glycine at VIAAT (Gasnier, 2000) and therefore, will be primarily determined by the relative presynaptic cytosolic concentrations of the two inhibitory neurotransmitters.

In active terminals, GABA is synthesized from glutamate by two isoforms of the glutamate decarboxylase enzyme (GAD65/67; Martin and Rimvall, 1993; Kakizaki et al., 2015), whereas the concentrative power of GlyT2, a $3 \mathrm{Na}^{+}$-coupled glycine transporter (Roux and Supplisson, 2000), is required to increase basal glycine concentration to the appropriate levels for VIAAT uptake (Gomeza et al., 2003; Rousseau et al., 2008; Apostolides and Trussell, 2013). Experimental evidence confirms that the cytosolic concentration of glycine and GABA does indeed influence synaptic vesicle content (Rousseau et al., 2008; Apostolides and Trussell, 2013; Ishibashi et al., 2013). Furthermore, two in vitro studies have succeeded in sampling the inhibitory transmitter content of VIAAT-expressing vesicles at single terminals and found evidence that the mIPSCs phenotypes were not homogenous. Instead, GABA-, glycine- and mixed mIPSCs were all detected at some individual synapses, suggesting that the signaling phenotype of a single terminal may considerably vary from vesicle to vesicle (Katsurabayashi et al., 2004; Aubrey et al., 2007; Supplementary Figure S1).

Here, we record mIPSCs in networks of culture spinal cord neurons and extract the subpopulation of MIPSCs that originate from an individual terminal by simultaneously recording mIPSCs with a loose-cell patch-clamp electrode placed over a single pre-synaptic varicosity. Then, we examine whether vesicles originating from the same co-releasing terminal evoke homogenous postsynaptic currents, as expected if all of a presynaptic terminal's vesicles contain a similar concentration of GABA and glycine. In addition, we develop a simulation model of cotransmission to examine how mIPSC peak amplitude and charge transfer change as function of glycine vs. GABA release. Using activation kinetic schemes of GlyR and $\mathrm{GABA}_{\mathrm{A}} \mathrm{R}$, our simulations show that alterations in vesicular content would not compromised the strength, but rather would shape the time-course of postsynaptic inhibition.

\section{MATERIALS AND METHODS}

\section{Embryonic Mouse Spinal Cord Neurons}

Primary cultures of spinal cord neurons were prepared as described in Hanus et al. (2004) from embryonic day 13 or 14 (E13-14) C57BL/6J wild-type or heterozygous GlyT2-EGFP mouse pups (Zeilhofer et al., 2005). Embryos were obtained by cesarean section from pregnant mice anesthetized by intraperitoneal injection of ketamine-xylazine (100 and $10 \mathrm{mg} / \mathrm{kg}$ ) and killed by cervical dislocation. Spinal cords were dissected under sterile conditions into PBS with $33 \mathrm{mM}$ glucose at $\mathrm{pH}=7.4$ and then incubated in trypsin/EDTA solution $(0.05 \%$ v/v, Sigma, St. Louis, MO, USA) for $10 \mathrm{~min}$ at $37^{\circ} \mathrm{C}$. Cells were dissociated mechanically in a modified L15 Leibowitz's medium (Life Technologies, Cergy Pontoise, France) and plated at a density of $1.0 \times 10^{5}$ cells $/ \mathrm{cm}^{2}$ on sterilized glass coverslips coated with $60 \mu \mathrm{g} / \mathrm{ml}$ poly D-L ornithine and with medium containing $5 \%$ inactivated fetal calf serum (Sigma, St. Louis, MO, USA). To insure easy visualization of a few eGFP-GlyT2 positive axons and their boutons, each coverslip was composed of $5 \%-10 \%$ neurons from GlyT2-eGFP mice; the remaining $90 \%-95 \%$ neurons were from unlabeled WT littermates. Cells were maintained at $37^{\circ} \mathrm{C}$ in $5 \% \mathrm{CO}_{2}$ in serum-free Neurobasal ${ }^{\mathrm{TM}}$ medium containing supplement B27 (Invitrogen, Carlsbad, CA, USA; Brewer et al., 1993) for up to 3 weeks. Medium was changed every 4-5 days.

\section{Electrophysiology}

Whole-cell (WC) patch clamp recordings of spinal cord neurons (14-22 DIV) were performed at $30^{\circ} \mathrm{C}$. Voltage-clamp was imposed by a Multiclamp 700B amplifier controlled by pCLAMP 9 or 10 acquisition software (Molecular Devices). Currents were filtered at $4 \mathrm{kHz}$ and sampled at $20 \mathrm{kHz}$ using a Digidata 
1440A (Molecular Devices). Neurons were continuously bathed with an external solution containing (mM): $\mathrm{NaCl} 140, \mathrm{KCl}$ 2.4, $\mathrm{CaCl}_{2}$ 2, $\mathrm{MgCl}_{2}$ 2, Glucose 10, HEPES 10, $\mathrm{pH}=7.4$. WC patch clamped mIPSCs were recorded in the presence of $0.2 \mu \mathrm{M}$ of the sodium channel blocker tetrodotoxin (TTX) and $2 \mu \mathrm{M}$ of the benzodiazepine flunitrazepam. AMPA and NMDA receptors were blocked with $2 \mu \mathrm{M}$ NBQX (6-nitro-7sulfamoylbenzo[f] quinoxaline-2, 3-dione) and $5 \mu \mathrm{M}$ MK-801, respectively. When indicated $\mathrm{GABA}_{\mathrm{A}}$ receptors $\left(\mathrm{GABA}_{\mathrm{A}} \mathrm{Rs}\right)$ were blocked with $5 \mu \mathrm{M}$ gabazine (SR 95531), and glycine receptors (GlyRs) were blocked with $1 \mu \mathrm{M}$ strychnine. The majority of whole cell mIPSCs have fast rise times, and a few cells were found to have a correlation between their glycinergic mIPCS rise and decay time constants, suggesting that dendritic filtering of mIPSCs from more distant synapses influences the kinetic of some, but not all, events included in the WC mIPSC data (Supplementary Figure S2C; Gardner et al., 1999). There was no evidence of dendritic filtering at any of the single synapse mIPSCs, as expected for events that originated from synaptic terminals that are on, or very close to, the neuronal soma (Supplementary Figure S2C).

Patch-pipettes were pulled from borosilicate glass capillaries (Hilgenberg, Maisfeld, Germany) and pipettes for WC recording had typical resistances of 4-6 M $\Omega$. The mIPSCs were recorded at a holding potential $\left(\mathrm{V}_{\mathrm{H}}\right)$ of $-70 \mathrm{mV}$ (taking into account the junction potential) using pipettes filled with a standard internal

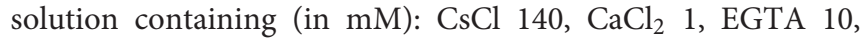
BAPTA 1, $\mathrm{MgCl}_{2}$ 1, Mg-ATP 4, QX314-Cl 5, Hepes 10, adjusted to $\mathrm{pH} 7.4$ with $\mathrm{CsOH}$. Loose-patch (LP) recording pipettes had resistances of 1-2 M $\Omega$ and LP mIPSCs were recorded at $0 \mathrm{mV}$. One out of every 10 attempts at obtaining a LP recording were successful. LP pipettes were filled with the high calcium external solution ( $4 \mathrm{mM} \mathrm{Ca}^{2+} ; 0 \mathrm{mM} \mathrm{Mg}^{2+}$ ), $0.2 \mu \mathrm{M}$ TTX, $2 \mu \mathrm{M}$ flunitrazepam, $2 \mu \mathrm{M}$ NBQX, $5 \mu \mathrm{M}$ MK-801. Baclofen, a $\mathrm{GABA}_{\mathrm{B}} \mathrm{R}$ agonist, was added to the extracellular solution to reduce the frequency of mIPSC when required (O'Brien et al., 2004). Unless indicated, drugs were purchased from Sigma (St. Louis, MO, USA) or Tocris Bioscience (Bristol, UK).

\section{Data Analysis}

Miniature synaptic currents were detected semi-automatically and analyzed using SpAcAn, a custom-made integral detection Igor package developed by Guillaume Dugué and Charly Rousseau and available at www.spacan.net. or in AxoGraph. LP and WC mIPSCs whose peak currents occurred simultaneously $(<0.6 \mathrm{~ms})$ and were verified to have a smooth rise and decay phase, as well as a strongly correlated peak amplitudes, were included in the analysis. Electrophysiological results are reported as mean $\pm \mathrm{SEM}$. All statistical tests were nonparametric and performed using Prism software unless indicated. The Mann-Whitney and Wilcoxon Matched-Pairs test was used to assess differences between two independent and two related samples respectively. For all tests, the number of asterisks $\left({ }^{*}\right)$ in the figures corresponds to level of significance: ${ }^{* * *} p<0.001$, ${ }^{* *} p<0.01$ and $* p<0.05$.

Populations of glycine and GABA mIPSCs recorded in the presence of SR 95331 or strychinine, respectively, were classified as glycinergic, GABAergic or mixed on the basis of their peak amplitude to charge transfer relationship and then fitted with a linear regression and $95 \%$ prediction intervals. We also attempted to classify mIPSC events by fitting their currents with biexponential and monoexponential fits (Jonas et al., 1993; Rahman et al., 2013) but found that the peak amplitude to charge relationship robust and fast (Supplementary Figure S2). We set a conservative limit of $\geq 30 \%$ to considering groups of single synapse mIPSCs as a separate population. This value was based on our pharmacological characterization of glycine and GABA mIPSCs.

\section{Numerical Simulation}

The set of linear differential equations that defined the GlyR and $G_{A B A} R$ kinetic models was numerically solved in Mathematica 11 using the Q-matrix approach (Colqhoun and Hawkes, 1995). The current amplitude corresponds to the summation of 120 GlyRs and $60 \mathrm{GABA}_{\mathrm{A}} \mathrm{Rs}$, with elementary currents of 1.05 and $3 \mathrm{pA}$ for the $\mathrm{GABA}_{\mathrm{A}} \mathrm{R}$ mono- and di-liganded receptors, respectively, and $5 \mathrm{pA}$ for GlyR. The rate constants are indicated in Figure $\mathbf{3 A}$, that correspond to the values determined by Burzomato et al. (2004) for GlyR and Labrakakis et al. (2014) for $\mathrm{GABA}_{\mathrm{A}} \mathrm{R}$ except for the dissociation rate constants that were slightly increased to match the experimental time course of the MIPSC and peak-charge amplitude relationship.

We used the simplified assumption of a monoexponential time course for the transient of GABA and glycine (AAN: amino-acid neurotransmitter) with a piecewise function:

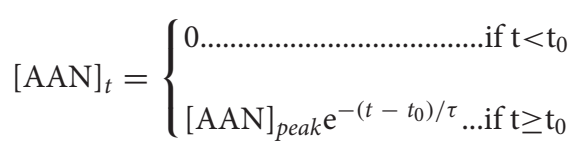

The time constant of the transient in Figure 3 was $\tau=0.7 \mathrm{~ms}$ and the $[\mathrm{AAN}]_{\text {peak }}=[\mathrm{Gly}]_{\text {peak }}+[\mathrm{GABA}]_{\text {peak }}=3 \mathrm{mM}$ (Beato, 2008). The time offset $\left(t_{0}\right)$ was $2 \mathrm{~ms}$ and the time of integration was $200 \mathrm{~ms}$.

The simulated mixed mIPSC corresponds to the algebraic sum of the glycine and GABA mIPSCs. We used the FindMinimum and NIntegrate functions of Mathematica 11 (Wolfram Research) to determine the peak amplitude and charge transfer of simulated mIPSCs.

The parameter $\alpha$ set the relative glycine concentration in the transient:

$$
\alpha=\frac{[G l y]_{t r}}{[G l y]_{t r}+[G A B A]_{t r}}
$$

In Figure 4 and Supplementary Figure S3, we examined the distribution of mIPSC phenotypes that were simulated with a broad variation in $[\mathrm{Gly}]_{\text {peak }}$ and $[\mathrm{GABA}]_{\text {peak }}$ and/or $\mathrm{GABA}_{\mathrm{A}}$ and GlyR. Normal distributions of $[\mathrm{Gly}]_{\text {peak, }}[\mathrm{GABA}]_{\text {peak }}$ and/or $\mathrm{GABA}_{\mathrm{A}}$ and GlyR were generated using the Random Variate and NormalDistribution functions of Mathematica with $[\mathrm{Gly}]_{\text {peak }}=\mathcal{N}\left[3 \alpha,(3 \alpha \mathrm{CV})^{2}\right]$ and $[\mathrm{GABA}]_{\text {peak }}=\mathcal{N}[3(1-\alpha)$, $\left.(3(1-\alpha) C V)^{2}\right]$. Accordingly, the average $[\mathrm{AAN}]_{\text {peak }}$ was constant $(3 \mathrm{mM})$ in all simulations. 


\section{Ethics Statements}

This study was carried out in accordance with the recommendations of guidelines of the Centre National de la Recherche Scientifique. The protocol was approved by the CNRS under number 02235.02 of the general agreement C750520.

\section{RESULTS}

\section{Identification of mIPSCs From Individual Terminals Using a Combination of Loose-Patch and Whole-Cell Electrophysiology in Cultured Spinal Neurons From GlyT2-eGFP Mice}

We combined the spinal cords of wild-type and GlyT2-eGFP (5-10\%) embryos (Zeilhofer et al., 2005) and made low-density cultures of eGFP-expressing neurons that were used for electrophysiological experiments at DIV14-21. When viewed under fluorescent light, we observed thin, parallel neurites with beaded varicosities (1.05 $\pm 0.2 \mu \mathrm{m}, n=30)$, suggestive of axons (Figure 1A). The GlyT2-eGFP ${ }^{+}$beaded varicosities rapidly accumulated the styryl dye FM 4-64, a marker of cycling presynaptic vesicles (Figure 1B), confirming that they correspond to presynaptic terminals.

Next, we voltage-clamped $\left(\mathrm{V}_{\mathrm{H}}=-70 \mathrm{mV}\right)$ the cell body of an $\mathrm{eGFP}^{-}$neuron that appeared to have direct contact with one or a few $\mathrm{eGFP}^{+}$varicosities at or near to its soma, and recorded WC mIPSCs in the presence of TTX (Figure 1C). WC mIPSCs are heterogeneous because they correspond to the postsynaptic neurons response to the spontaneous release of single synaptic vesicle at one of its many inhibitory terminals (Hubbard et al., 1967). To identify the specific subset of mIPSCs that originated from a single GlyT2-eGFP ${ }^{+}$varicosity, we simultaneously recorded extracellular mIPSCs from a second LP recording electrode $\left(\mathrm{V}_{\mathrm{H}}=0 \mathrm{mV}\right)$ placed directly over a single synapse, identified by its $\mathrm{eGFP}^{+}$varicosity, located at or near to the soma of the recorded neurons (Figure 1C; Forti et al., 1997). Single-synapse mIPSCs were identified from whole cell mIPSCs (inward) that were time- and amplitude-locked to extracellular LP mIPSCs (outward, Figures 1C,D). LP-mIPSCs were never
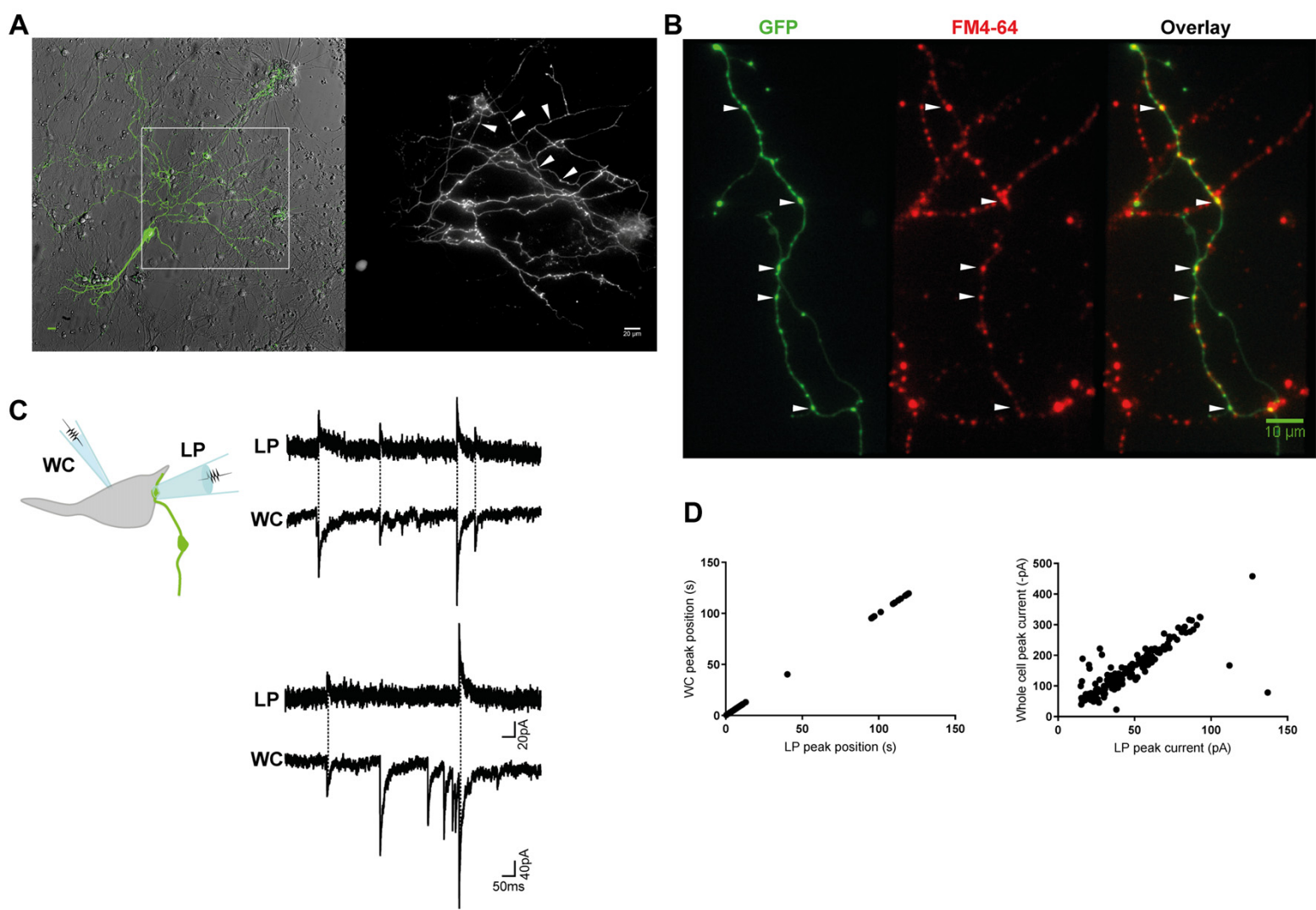

FIGURE 1 | Miniature inhibitory postsynaptic currents (mIPSCs) were recorded from individual inhibitory terminals. (A) GlyT2-eGFP+ neurons and neurites were visible in our spinal cord cultures. eGFP+ neurites with a parallel structure and beaded varicosities $\left({ }^{*}\right)$ were labeled with FM 4-64 dye (B), confirming they are glycine-containing presynaptic terminals. Scale bars are $10 \mu \mathrm{m}$. (C) Cartoon of the paired recording configuration that allowed identification of mIPSCs that originated from an individual inhibitory terminal (top). Postsynaptic mIPSCs were simultaneously recorded with the whole-cell patch clamp pipette (WC) and the loose-patch clamped pipette (LP). The traces (middle and bottom) are a continuous $2 \mathrm{~s}$ recording from one WC-LP pair. (D) The LP and whole cell mIPSCs from the same recording as displayed in (C), were strongly correlated in time and amplitude, as expected from an extracellular and intracellular measurement of the same signal. 
detected if the LP-pipette was not centered precisely on the GlyT2-eGFP ${ }^{+}$varicosity, consistent with the prediction that the LP-pipette will detect less than $1 \%$ of currents that originate outside the LP pipette (Forti et al., 1997) and suggestive that detection of current from two independent synases is unlikely.

\section{GABA- and Glycine-Only mIPSCs Events Were Defined Based on Their Peak Amplitude to Charge Relationship}

Although GABA and glycine activate ligand-gated chloride channels with distinct biophysical and pharmacological properties, GABAergic and glycinergic mIPSCs are difficult to separate because of their overlapping receptor kinetics (Burzomato et al., 2004; Labrakakis et al., 2014). We used flunitrazepam, a positive allosteric modulator of $\mathrm{GABA}_{\mathrm{A}}$ receptors, to selectively slow the decay of GABAergic mIPSCs and allow a crude separation of GABA vs. glycine mIPSCs based on their peak amplitude and charge transfer (Figures 2A,B). Nevertheless, the two mIPSC populations were highly variable both within and between neurons (Figure 2C; $n=15$ cells,
600 mIPSC events each). The variability is attributable to the presence of multiple independent inhibitory connections with potential differences in: receptor numbers, receptor subunit composition, synaptic architecture, as well as synaptic vesicle content (Ropert et al., 1990; Frerking et al., 1995; Auger and Marty, 1997; Nusser et al., 1997) and dendritic filtering (Gardner et al., 1999). This variability was not reduced by analyzing data from neurons prepared from the same animals, or on the same number of days in vitro (data not shown). Linear regressions of the peak amplitude vs. charge data and $95 \%$ prediction intervals frame the GABA and glycine mIPSC populations and were used to classify pure and mixed phenotypes (Figure 2C). When we recorded whole cell mIPSCs in the absence of strychnine and SR 95531, and selected mIPSC events with clear biphasic decay currents characteristic of mixed GABA/glycine cotransmission (Jonas et al., 1998; Lu et al., 2008), these events mapped in-between the GABA and glycine mIPSC prediction intervals on graphs of peak amplitude vs. charge (Figure 2D) or within the GABA mIPSC prediction intervals (Figure 2E). Thus, the linear regression and $95 \%$ prediction intervals of the glycine peak to charge
A

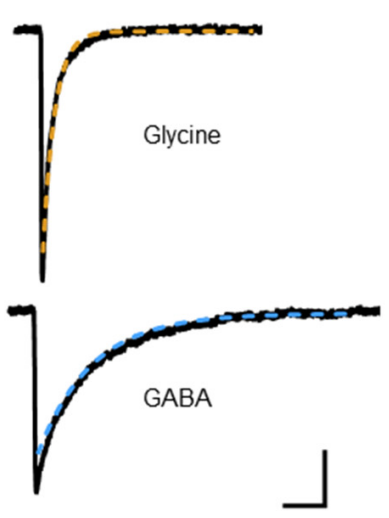

C

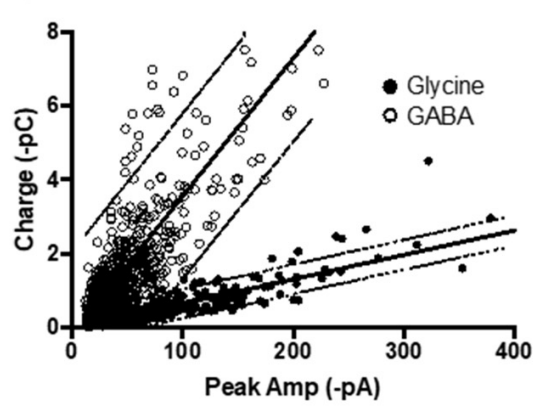

B
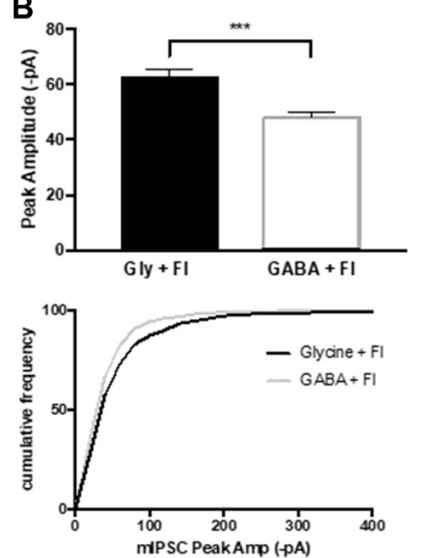

D

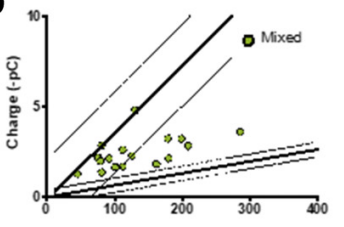

E

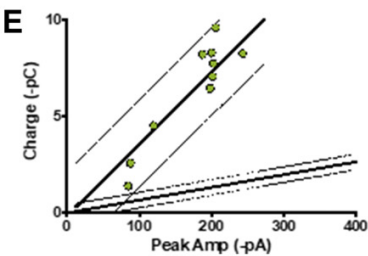

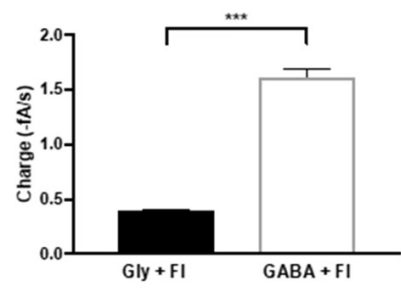
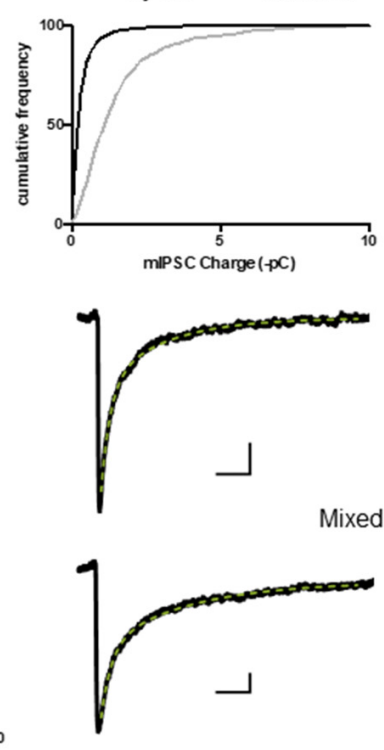

FIGURE 2 | GABA, glycine and mIPSCs were defined on the basis of their peak current and charge transfer. (A) Average current traces of glycinergic and GABAergic mIPCs were recorded in whole-cell configuration in the presence strychnine or SR95331 and decays fitted with a single exponential (orange and blue) respectively. (B,C) The peak current (I) to charge ratio of GABA and glycine mIPSC ( $n=600$ events from 15 neurons each) were used to define $95 \%$ prediction intervals (gray lines) for these two mIPSC phenotypes. (D,E) Two example populations of mixed mIPSCs recorded in the absence of strychnine or SR 95331 and selected on the basis of their biphasic decay current (double exponential fit (green)). Mixed mIPSCs mapped between the two 95\% prediction intervals or were misidentified as GABAergic, depending on the size of their GABA component. 
data provides functional limits to define glycinergic and mixed mIPSCs. In contrast, the GABAergic mIPSC data was not able to differentiating between mixed and GABAergic mIPSCs, especially when mixed mIPSC currents had a large GABA component (Figure 2E).

To explore all possible phenotype outcomes in response to variable GABA and glycine vesicular release, we simulate glycinergic, GABAergic and mixed mIPSCs with activation kinetic models for $\mathrm{GABA}_{\mathrm{A}} \mathrm{R}$ and GlyR that have been previously established (Burzomato et al., 2004; Labrakakis et al., 2014; Figures $3 \mathbf{A}, \mathbf{B})$. We limited our simulations to the simplest, linear substitution of GABA by glycine, keeping a constant [neurotransmitter release] $\left(\mathrm{AAN}_{\text {peak }}=3 \mathrm{mM}, \tau_{\mathrm{r}}=0.7 \mathrm{~ms}\right.$ (Beato, 2008), Figure 3C). Therefore, increasing $\alpha$ potentiates the glycine component and decreases the GABA component of mixed mIPSCs (Figures 3D-F) in such a way that the increase in peak amplitude may compensate for the reduction in charge transfer, thus preserving the strength of synaptic inhibition (Figure 3G).
To map a more realistic distribution of inhibitory phenotypes, we plot the peak-charge amplitude distribution of simulated mIPSCs for a randomly generated number of postsynaptic receptors and peak concentration transients (see "Materials and Methods" section). First, we plot the smooth density histograms for 200 simulated mIPSCs when there is a unique, pre- or post-synaptic source of variability with a coefficient of variation of $0.2\left(\mathrm{CV}_{\mathrm{R}}=0.2\right.$ or $\mathrm{CV}_{\mathrm{AAN}}=0.2$, Supplementary Figure S3). Supplementary Figure S3 illustrates that a lower variability of the GABA mIPSCs is expected when $\alpha$ values are low, because $\mathrm{GABA}_{\mathrm{A}} \mathrm{R}$ receptors are almost saturated by $3 \mathrm{mM}$ GABA transient $\left(\mathrm{EC}_{50}=0.81 \mathrm{mM}\right.$ for $\mathrm{GABA}_{\mathrm{A}} \mathrm{R}$ and $2.68 \mathrm{mM}$ for GlyR, with comparable apparent hill-coefficients of 2.17 and 2.06, respectively). Then we map the distribution of 500 randomly simulated mIPSCs with average $\alpha$ values ranging from 0 (pure GABA) to 1 (pure Glycine) by 0.05 step increments (Figure 4A), with high pre- $\left(C V_{R}=0.4\right.$, Figure $4 B$ ) and post- $\left(\mathrm{CV}_{\mathrm{AAN}}=0.4\right.$, Figure $\left.4 \mathrm{C}\right)$ synaptic variability. By definition, the simulated mIPSCs are mixed and have
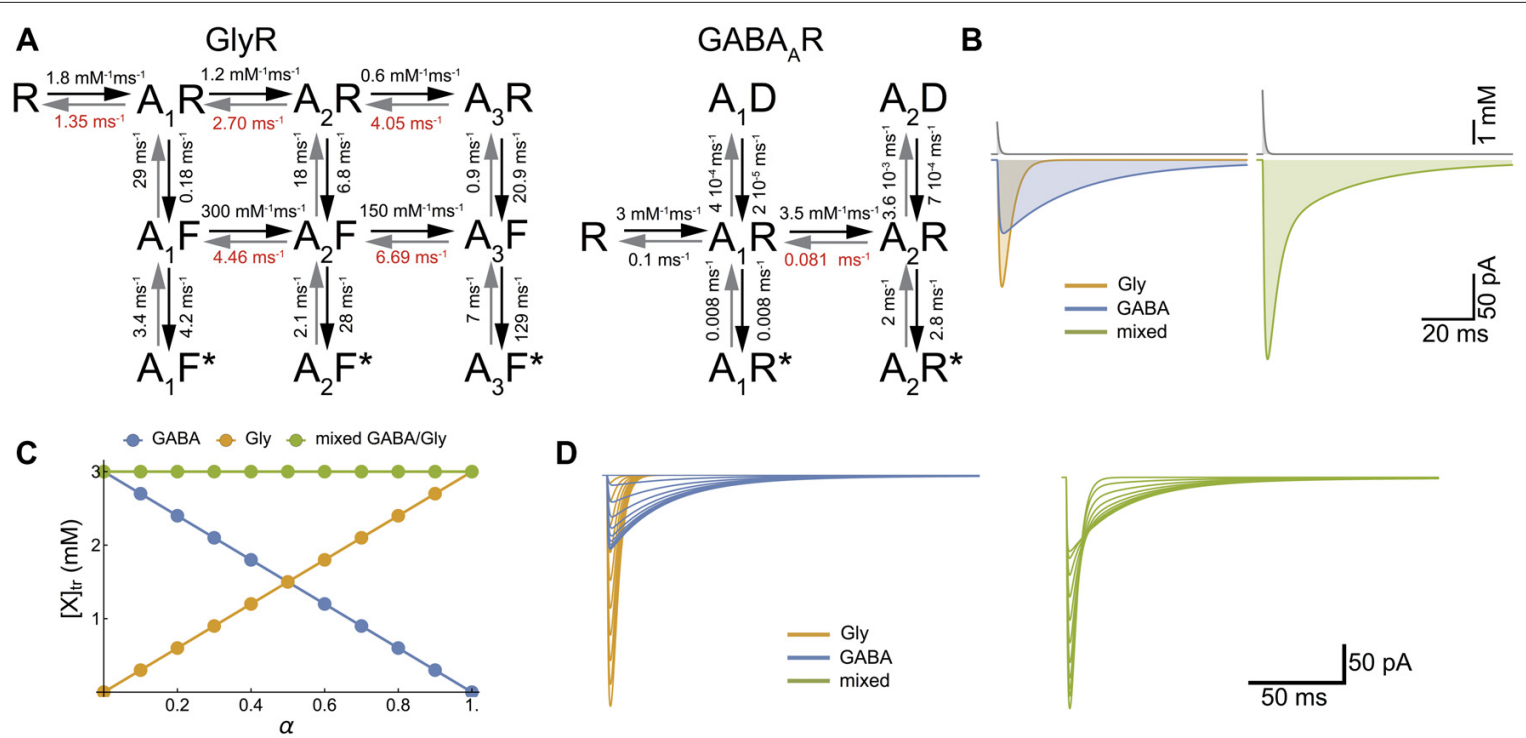

D
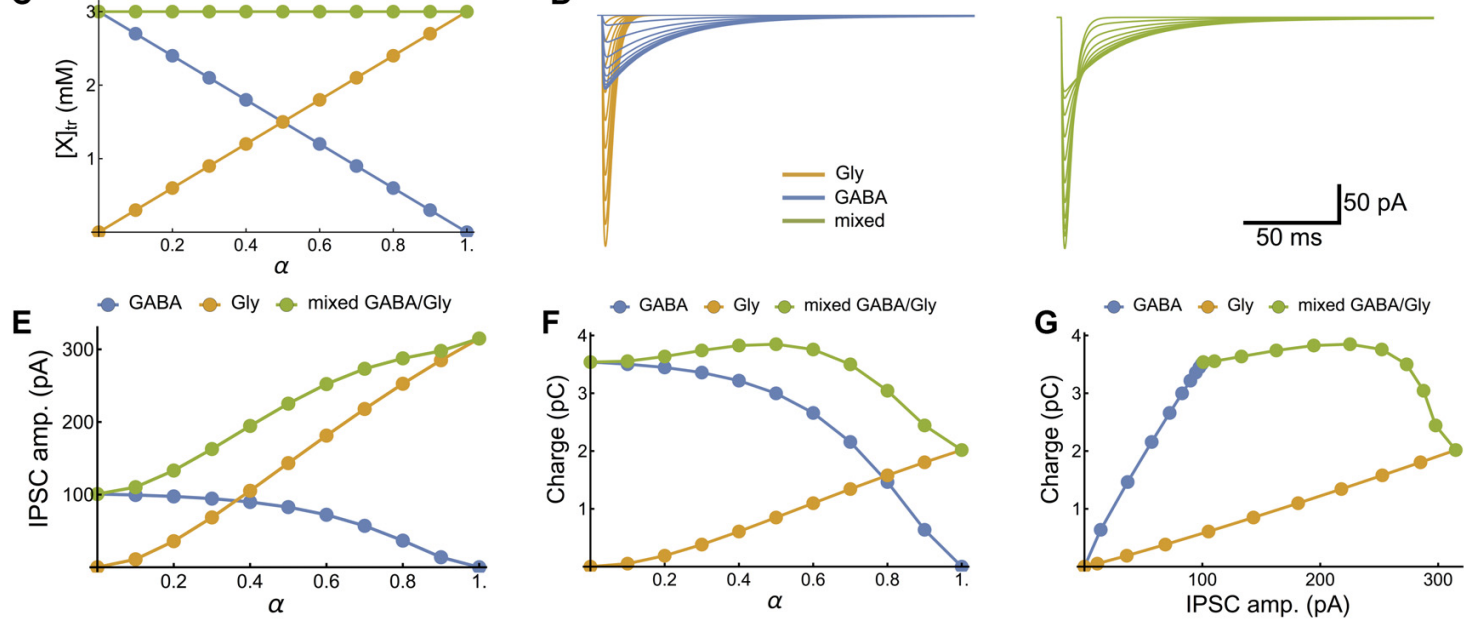

FIGURE 3 | Model of cotransmission shows that swapping glycine for GABA in the neurotransmitter transient maintains the strength of synaptic inhibition. (A) Kinetic schemes for the activation of GlyR (Burzomato et al., 2004) and GABA $A_{A}$ (Jones and Westbrook, 1995; Labrakakis et al., 2014) that were used for the numerical simulations. We adopted the set of rate constants determined by Burzomato et al. (2004) and Labrakakis et al. (2014), with the exception of the dissociation rate constants, indicated in red, that were adjusted for matching the time course of our recorded mIPSCs ( $\tau=6.4$ ms and 34.3 ms for glycine and GABA IPSC respectively). (B) Numerical simulations of the mIPSCs evoked by concentration transient (1.5 mM) of glycine or GABA applied alone (left) or together (right). The concentration scale is the total concentration of neurotransmitter. (C) Inverse relationships of GABA and glycine concentrations for increasing values of $\alpha$, which is the fraction of glycine released during each transient, assuming constant vesicular release (3 mM). (D-G) Numerical simulations of glycinergic, GABAergic and mixed mIPSCs when $\alpha$ increased from 0 to 1 by increments of 0.1 , showing the current traces (D), the IPSC peak amplitudes (E), the IPSC charge transfer (F) and the IPSC charge-amplitude relationships (G). 

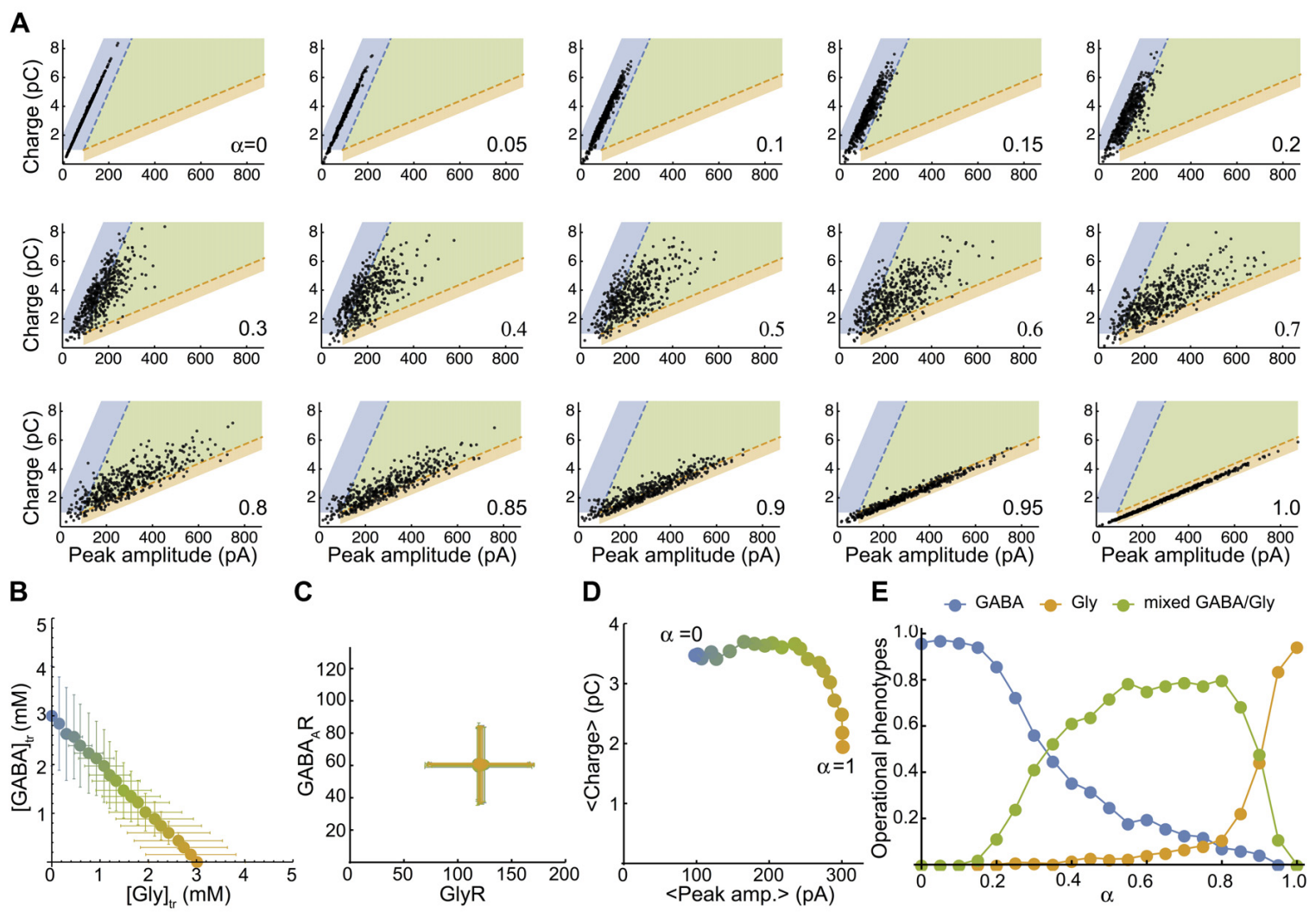

FIGURE 4 | The simulated mixed mIPSC phenotypes shifts as function of the proportion of glycine and GABA coreleased. (A) Simulated-mIPSC charge-amplitude distribution for increasing $\alpha$ values. Each panel shows the charge-amplitude distribution of 500 randomly simulated mIPSCs for the $\alpha$ value indicated. We defined three areas as GABAergic (blue), glycinergic (orange) and mixed (green) to operationally sort individual mIPSC phenotypes with similar threshold criteria that were used experimentally. (B) Parametric plot of the average GABA-glycine peak concentration in the transient as function of $\alpha$. Each value was randomly generated from normal distributions as function of $\alpha$ with $\mathrm{CV}_{\mathrm{AAN}}=0.4$ ([gly]: $3 \alpha \pm 1.2 \alpha \mathrm{mM}$ and [GABA] $=3(1-\alpha) \pm 1.2(1-\alpha) \mathrm{mM}$ ). (C) Plot of the average number of $\mathrm{GABA}_{A} R$-GlyR randomly generated from normal distributions with $C V_{R}=0.4$ (120 \pm 48 GlyRs and $60 \pm 24 \mathrm{GABA}_{A}$ Rs). (D) Plot of the average charge-peak amplitude. (E) Proportions of GABAergic, glycinergic and mixed phenotypes of simulated mIPSCs as function of $\alpha$. Each point in (B-D) represents the average value of the distribution for an $\alpha$ value and the color blend is a linear function of $\alpha$ between pure GABA $(3 \mathrm{mM}$, blue, $\mathrm{a}=0)$ and pure glycine $(3 \mathrm{mM}$, orange, $\alpha=1)$.

Figure 4A has been reproduced from Aubrey et al. (2007).

two components when $0<\alpha<1$ and would therefore be arbitrarily qualified as mixed, even if one component is small and the mIPSC resembles pure GABAergic or pure glycinergic events. Therefore, we delimit three areas in the charge-peak amplitude plot (Figure 4A) for the attribution of GABAergic (blue area), glycinergic (orange area) and mixed phenotypes (green area), based on the $95 \%$ prediction from the linear regression of the experimental values for charge-peak amplitude. The average peak-charge amplitudes for each $\alpha$ values follow the model predictions (Figure 4D) and the repartition of mIPSC phenotypes as function of $\alpha$ (Figure 4E) shows that $10 \%$ GABA release $(\alpha=0.9)$ reduces the glycinergic component of the mixed mIPSCs by $50 \%$, whereas in contrast a similar reduction in GABAergic phenotypes is not achieved until $\alpha=0.3$. This finding is consistent with our experimental data (Figures 2D,E) and indicates that mixed mIPSCs with small glycine components are likely to be characterized as a GABAergic phenotype. Overall, the model confirms that neurotransmitter release by vesicles containing higher proportions of glycine than
GABA will evoke mixed mIPSCs that have intermediate peak amplitude-charge relationships, falling in-between the GABA and glycine prediction intervals defined by our experimental data. When $\alpha=0.45-0.85$ the model predicts that mixed phenotypes will be the dominant phenotype, with $<20 \%$ of mixed events being mischaracterized.

\section{A Combination of Mixed and Glycinergic mIPSCs Were Detected at Some Individual Terminals}

Individual-terminal mIPSCs were recorded in the absence of strychnine and SR 95331, and analyzed when the peak amplitude and charge values were measurable in $\geq 25$ LP-linked mIPSCs. We classified the mIPSC phenotype from 18 individual terminals. In 4 of the 18 synapses only glycine mIPSC were detected (Figure 5A), with a reduced co-efficients of variation $(\mathrm{CV})$ compared to glycine mIPSCs from whole cell recording $(0.42 \pm 0.5$, range $0.30-0.51$; and $0.65 \pm 0.05$, range 

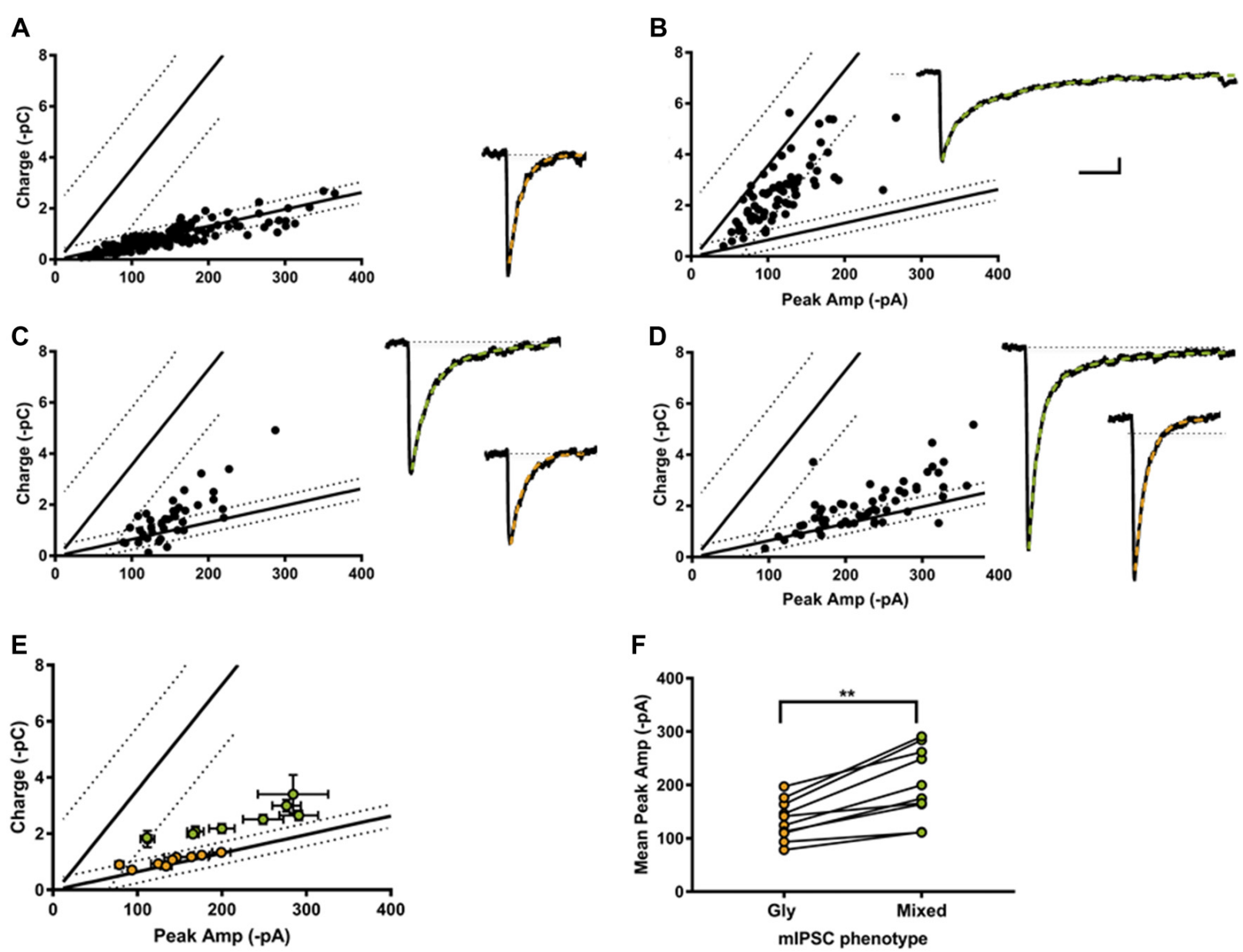

FIGURE 5 | Most individual inhibitory synapses had a combination phenotype comprised of both glycine and mixed mIPSCs. Examples of single synapse peak amplitude-charge relationships (left) and average mIPSCs (10 events each, right) with their decay current fitted with a single (orange) or double exponential (green). $4 / 18$ of the recorded synapses were purely glycinergic (A), and 5/18 were purely mixed (B). The other $9 / 18$ synapses displayed a combination of mixed and glycine mIPSCs (C,D). (E) Average peak current-charge relationship of the glycine (orange) and mixed (green) mIPSCs identified in the nine combination synapses. (F) Glycine mIPSC peak amplitudes were always smaller than the mixed mIPSC peak amplitude, as expected from a compound GABA+glycine mIPSC event.

0.25-0.86, respectively). The rest (14/18) were cotransmission terminals, with a substantial proportion of mixed mIPSCs. According to our classification system, we found that $36 \%$ $(5 / 14)$ of the cotransmission terminals we sampled had a homogenous mixed mIPSC phenotype as hypothesized (Figure 5B). The majority $(64 \%, 9 / 14)$ had a heterogeneous phenotype made up of a combination of mixed and glycineonly mIPSCs (Figures 5C,D). In these combination synapses, the mixed eIPSCs were always larger than glycine-only mIPSCs, as predicted for an additive current, and the mixed current was carried primarily by glycine (Figures 5E,F). Examination of the raw mIPSCs currents grouped into their designated phenotypes (averaged from 10 consecutive events), demonstrates that phenotypically glycinergic mIPSCs have characteristic fast monophasic decay kinetic (Figures 5A,C,D). In contrast, mIPSCs events that fell into the mixed or GABA phenotype regions all had a discernable biphasic kinetics (Figures 5B-D) indicating this population corresponded to mixed events. Together, these data supports the identification of distinct mixed and pure mIPSC phenotypes in combination synapses.

\section{DISCUSSION}

\section{Heterogeneity of GABA/Glycine Vesicular Content as a Presynaptic Source of mIPSC Variability}

Because identifying the glycine and GABA components in individual mixed IPSCs is not straightforward, we previously used a giant-synapse, made from a secretory BON cell and a sniffer HEK cell, to sample all vesicular phenotypes when a VIAAT-expressing BON cell had access to both neurotransmitters (Aubrey et al., 2007). In this cellular model, sniffer HEK cells expressed GABA and glycine receptors that had cationic and anionic permeability respectively, thus 
GABA- and glycine-evoked currents had opposite polarities and could be identified unambiguously (Aubrey et al., 2007, Supplementary Figures S1A-C). Surprisingly, the distribution of pure and mixed events from individual co-releasing $\mathrm{BON}$ cells suggested heterologous vesicular GABA/glycine content (Aubrey et al., 2007, Supplementary Figure S1C), as reported in acutely dissociated spinal cord neurons (Katsurabayashi et al., 2004). We can excluded a significant contribution of the sniffer cell in the BON/HEK model because scanning across the entire sniffer HEK cell surface with brief iontophoretic applications of a fixed [GABA] and [glycine] evoked stable biphasic currents (Supplementary Figures S1D,E), again supporting heterogeneous vesicular content that favors glycineor GABA-like mIPSCs.

In the present work, we combined LP extracellular recordings with WC recordings to sample mIPSCs from single inhibitory varicosity in spinal cord cultures from GlyT2:EGFP mice. We have shown previously that evoked IPSCs from GlyT2expressing neurons are predominately mixed, with a larger glycinergic component (Rousseau et al., 2008). As expected, we detected mixed mIPSCs in the majority $(78 \%)$ of GlyT2-GFP ${ }^{+}$ synapses sampled and found that most mixed GABA/glycine synapses signaled with a combination of pure and mixed mIPSCs. This phenotypic heterogeneity may have a presynaptic origin that results from variability in the accumulation and packaging of GABA and glycine in VIAAT-containing synaptic vesicles, similar to the BON/HEK model system (Aubrey et al., 2007; Supplementary Figure S1), however we cannot rule out a postsynaptic origin because inhibitory synapses are dynamic structures (Choquet and Triller, 2013), with glycine and $\mathrm{GABA}_{\mathrm{A}}$ receptors being constantly trapped or exchanged between gephyrin containing nano-domains (Calamai et al., 2009; Maric et al., 2014; Tyagarajan and Fritschy, 2014; Alvarez, 2017; Pennacchietti et al., 2017). In addition, varicosities are larger structures than the small en passant boutons of typical central synapses that may contain multiple active zones facing postsynaptic clusters with different receptor compositions (Nusser et al., 1997; Biró et al., 2006; Lévi et al., 2008). When we generated simulated mIPSCs including a pre- and a post-synaptic source of variability (Supplementary Figure S3), we found that both were able to recapitulate the mostly glycinergic mIPSC distributions observed experimentally. We did not attempt to differentiate the source of variability any further in the present work.

\section{mIPSC Detection Bias}

The distribution of mIPSC phenotypes, which is based on their peak to charge relationship, indicates that single varicosities predominantly signal with glycine in these cultures $(\alpha \geq 0.7)$. This dominant glycinergic phenotype was anticipated because: 1. all the synapses sampled had GlyT2-eGFP ${ }^{+}$presynaptic varicosities. 2. Glycine mIPSCs have faster kinetics and larger peak amplitude than GABA mIPSCs. As a result, 3. time-integration of mIPSCs was more consistently resolved for glycine events than for GABA events because often GABA mIPSCs that did not return to baseline before a subsequent mIPSC occurred and thus could not be reliably integrated.
4. Mixed mIPSCs with a high or low $\alpha$-values are likely to be mis-classified, although mixed mIPSCs with small GABA components $(\alpha>0.9)$ were more easily detected than those with small glycine components $(\alpha<0.3)$. 5. Finally, mIPSCs with larger peak amplitudes, typically carried by glycine currents in these cultures, were more likely to be detected by the low resistance, $\mathrm{LP}$ recordings.

\section{A Model to Study Cotransmission}

We modeled mixed mIPSCs as the summation of the $\mathrm{GABA}_{\mathrm{A}} \mathrm{Rs}$ and GlyRs mediated currents activated by a fast synaptic transient of GABA and glycine. Each randomly generated transient aims to represent the possible content of one VIAAT expressing vesicle. As the time course of glycine and GABA in the synaptic cleft have been thoroughly modeled (Overstreet and Westbrook, 2003; Beato, 2008), we used a fixed average peak concentration of $3 \mathrm{mM}$ and a synaptic transient time-constant of $0.7 \mathrm{~ms}$ for the simulation. We fixed the peak-concentration transient because the amount of neurotransmitter stored in a vesicle may be limited by VIAAT thermodynamics, VIAAT kinetics or set by other vesicular factors (Edwards, 2007).

We used kinetic models and rate constants well-established for both receptors (Burzomato et al., 2004; Labrakakis et al., 2014), and assumed for simplicity that glycine and GABA act independently, although it has been shown that GABA/glycine corelease accelerates the kinetics of glycinergic IPSCs in pure glycinergic synapses ( $\mathrm{Lu}$ et al., 2008). The distribution of randomly generated simulated mIPSCs on the charge-peak amplitude plot provided a graphical overview of all transitions between pure GABAergic and pure glycinergic phenotypes when the proportion of glycine in the neurotransmitter transient is sequentially increased. We operationally distinguished pure and mixed phenotypes for individual mIPSCs based on their location on three experimentally determined areas in the charge-peak amplitude plot. The distribution of "pure" GABAergic, mixed and "pure" glycinergic phenotypes shows that "pure" glycinergic phenotype is only compatible with pure glycine release since $\alpha=0.95$ (about $150 \mu \mathrm{M}$ GABA and $2.85 \mathrm{mM}$ Glycine) is enough to evoked mixed phenotypes. In contrast "pure" GABAergic phenotypes are reported up to $\alpha=0.2$ (about $2.4 \mathrm{mM}$ GABA and $0.6 \mathrm{mM}$ glycine), indicating that minor glycine corelease may more easily go unnoticed than minor GABA corelease. This asymmetry reflects the apparent saturation of $\mathrm{GABA}_{\mathrm{A}} \mathrm{Rs}$ with a $3 \mathrm{mM}$ GABA transient.

\section{Functional Roles for GABA/Glycine Corelease}

GABA/glycine co-signaling is habitually thought to be a property of immature inhibitory synapses in the spinal cord, brainstem and granular layer of the cerebellum that diminishes during postnatal development, with few exceptions (Inquimbert et al., 2007; Bhumbra et al., 2012). Indeed mixed GABA/glycine cotransmission was initially detected in juvenile rat spinal and brainstem motoneurons (Jonas et al., 1998; O’Brien and Berger, 
1999; Russier et al., 2002) and lamina I and II of the spinal cord dorsal horn (Keller et al., 2001). Furthermore, a critical shift toward pure glycinergic transmission takes place during the postnatal maturation in spinal cord locomotor centers (Gao et al., 2001) and brainstem auditory nuclei where the large amplitude and rapid decay of glycinergic IPSCs provide the microsecond precision needed for the processing and the coding of acoustic information (Brand et al., 2002; Nabekura et al., 2004).

However, corelease with or without cotransmission persists in adults at some synapses, suggesting a continuing specific need for each neurotransmitter. In the superficial lamina of the spinal cord, GABA and glycine cotransmission is replaced by pure glycinergic transmission after P23 (Keller et al., 2001). Vesicular corelease persists in into adulthood however, and coreleased GABA influences the release probability by acting at presynaptic GABA $_{B}$ R (Chéry and de Koninck, 2000). Furthermore, extrasynaptic $\mathrm{GABA}_{\mathrm{A}}$ receptor signals can be detected at higher stimulation intensities (Chéry and de Koninck, 1999). At physiological temperatures evidence suggests that GABA and glycine corelease may not contribute to spillover and tonic inhibition in the dorsal horn of the spinal cord, as the diffusion of GABA and glycine out of the synaptic cleft is readily controlled by transporters in this region (Mitchell et al., 2007). Nevertheless, spillover of synaptically released glycine has been shown to potentiate the NMDA responses in the superficial dorsal horn of the spinal cord, by increasing the occupancy of the NMDA receptor coagonist site (Ahmadi et al., 2003). The same developmental pattern of inhibitory transmitter use has been reported in the rat MNTB, where GABA/glycine cotransmission is detected until P9-P12 after which time pure glycinergic transmission dominates (Awatramani et al., 2005). Again vesicular corelease persists in older animals, and coreleased GABA has been shown to shorten glycinergic mIPSC decay times here ( $\mathrm{Lu}$ et al., 2008). In the central nucleus of the inferior colliculus of the auditory midbrain, GABA and glycine cotransmission persists in brain slices from P19 to P35 mice. Coreleased GABA and glycine evoke IPSCs with nearly identical amplitude and time course, suggesting that GABA and glycine are operationally fully interchangeable in this nucleus, thus securing inhibitory signaling by redundancy (Moore and Trussell, 2017). Finally, in the cerebellum of juvenile rats, inhibitory corelease occurs between Golgi cells and vestibulocerebellar Unipolar Brush Cells (Dugué et al., 2005; Rousseau et al., 2012), and once again evidence suggests that the transmission phenotype is under postsynaptic control. Interestingly, the phenotype of transmission in this region is not fixed developmentally, but seems to be coordinated with the phenotype of the glutamatergic input onto the Unipolar Brush Cell (Rousseau et al., 2012).

Our data suggests that a dynamic vesicular GABA/glycine balance at individual synapses may contribute to the tuning of phasic synaptic inhibition in spinal neurons. If the origin of the variability is indeed the neurotransmitter content in presynaptic vesicles, then glycine IPSC kinetics ( $\mathrm{Lu}$ et al., 2008) and the probability of transmitter corelease (where $\mathrm{GABA}_{\mathrm{B}}$ receptors are expressed (Chéry and de Koninck, 1999, 2000) would also contribute to this fine tuning.

\section{Possible Mechanisms for Vesicular GABA/Glycine Variations at Single Terminals}

The mechanisms that specify or regulate the vesicular GABA/glycine content at mixed synapses are not well understood. As previously discussed, changes to GABA (Mathews and Diamond, 2003; Wang et al., 2013) and glycine supply/resupply (Rousseau et al., 2008; Apostolides and Trussell, 2013; Ishibashi et al., 2013) can strongly shift the GABA/glycine balance and alterations in IPSC characteristics can be observed within minutes. Indeed, metabolic alteration such as these have been implicated in disease states including chronic pain (Coull et al., 2003; Imlach et al., 2016; Takazawa et al., 2017) and amyotrophic lateral sclerosis (Medelin et al., 2016).

With an apparent lower affinity for glycine than for GABA (about 25 and $6 \mathrm{mM}$, respectively), VIAAT uptake is likely to be rate limiting and a major source of variability for vesicular loading (Burger et al., 1991; Gasnier, 2000; Edwards, 2007; Farsi et al., 2016; Takamori, 2016). In addition, VIAAT has presumably the lowest driving force for uphill transport among the vesicular transporters (Edwards, 2007), being coupled to the exchange of a single $\mathrm{H}^{+}$(Hell et al., 1991; McIntire et al., 1997; Farsi et al., 2016) and with smaller protonmotive force (Egashira et al., 2016). If VIAAT kinetic is limiting for filling vesicles, as suggested by a slow recovery from synaptic depression (Katsurabayashi et al., 2004; Rousseau et al., 2008; Wang et al., 2013; Yamashita et al., 2018), then the initial vesicular content may continue to change as VIAAT exchanges a fast filling neurotransmitter (presumably GABA) with cytosolic glycine, providing opportunity for alterations in the transient neurotransmitter composition.

Other potential mechanisms include protein-protein interactions between the transmitter supply machinery and different populations of vesicles (Jin et al., 2003), differential modulation of the pool of cycling vesicle in response to presynaptic GABA or glycine supply (Mathews and Diamond, 2003; Wang et al., 2013; Truckenbrodt et al., 2018) or differential modes of GABA and glycine uptake by VIAAT (Aubrey et al., 2007). Given the diverse and highly regulated roles of the presynaptic terminal, this list is in not exhaustive.

In summary, this work adds to a growing body of evidence that suggest that the presynaptic terminal and neurotransmitter corelease can significantly regulate synaptic transmission. We present evidence that the GABA/glycine balance at individual coreleasing terminals is variable, and predict these variations would serve to fine tune the timing of inhibition and the integration of sensory inputs. Given the complexity and high level of control the presynapse has over synaptic vesicle release (Rizzoli and Betz, 2004; Edwards, 2007; Südhof, 2012), small, dynamic alternations in the balance of GABA/glycine signaling are possible and likely to contribute to synaptic plasticity.

Cotransmission is known to shape synaptic plasticity of other brain regions (Vaaga et al., 2014; Tritsch et al., 2016). For example, in the lateral habenula the GABA component of GABA/glutamate co-releasing inputs from the basal ganglia are selectively reduced in an animal model of depression. 
This deficiency is restored following sustained treatment with the antidepressant citalopram (Shabel et al., 2014). A similar reduction in the GABA component of mixed GABA/glutamate release has been observed in the same region in animal models of cocaine withdrawal, where it is attributed to a selective decrease in VIAAT expression in vesicles (Meye et al., 2016).

\section{AUTHOR CONTRIBUTIONS}

SS and KA conceived and planned the experiments. KA carried out the experiments and their analysis. SS carried out the modeling and simulations. SS and KA contributed to the interpretation of the results and wrote the manuscript.

\section{FUNDING}

This project received support from the Centre National de la Recherche Scientifique (CNRS), the ENS, the Institut National de la Santé et de la Recherche Médicale (INSERM), the program

\section{REFERENCES}

Ahmadi, S., Muth-Selbach, U., Lauterbach, A., Lipfert, P., Neuhuber, W. L., and Zeilhofer, H. U. (2003). Facilitation of spinal NMDA receptor currents by spillover of synaptically released glycine. Science 300, 2094-2097. doi: $10.1126 /$ science. 1083970

Alvarez, F. J. (2017). Gephyrin and the regulation of synaptic strength and dynamics at glycinergic inhibitory synapses. Brain Res. Bull. 129, 50-65. doi: 10.1016/j.brainresbull.2016.09.003

Apostolides, P. F., and Trussell, L. O. (2013). Rapid, activity-independent turnover of vesicular transmitter content at a mixed glycine/GABA synapse. J. Neurosci. 33, 4768-4781. doi: 10.1523/JNEUROSCI.5555-12.2013

Aubrey, K. R., Rossi, F. M., Ruivo, R., Alboni, S., Bellenchi, G., Le Goff, A., et al. (2007). The transporters GlyT2 and VIAAT cooperate to determine the vesicular glycinergic phenotype. J. Neurosci. 27, 6273-6281. doi: 10.1523/JNEUROSCI.1024-07.2007

Auger, C., and Marty, A. (1997). Heterogeneity of functional synaptic parameters among single release sites. Neuron 19, 139-150. doi: 10.1016/s08966273(00)80354-2

Awatramani, G. B., Turecek, R., and Trussell, L. O. (2005). Staggered development of GABAergic and glycinergic transmission in the MNTB. J. Neurophysiol. 93, 819-828. doi: 10.1152/jn.00798.2004

Beato, M. (2008). The time course of transmitter at glycinergic synapses onto motoneurons. J. Neurosci. 28, 7412-7425. doi: 10.1523/JNEUROSCI.058108.2008

Bhumbra, G. S., Moore, N. J., Moroni, M., and Beato, M. (2012). Co-release of GABA does not occur at glycinergic synapses onto lumbar motoneurons in juvenile mice. Front. Cell. Neurosci. 6:8. doi: 10.3389/fncel.2012.00008

Biró, A. A., Holderith, N. B., and Nusser, Z. (2006). Release probability-dependent scaling of the postsynaptic responses at single hippocampal GABAergic synapses. J. Neurosci. 26, 12487-12496. doi: 10.1523/JNEUROSCI.310606.2006

Brand, A., Behrend, O., Marquardt, T., McAlpine, D., and Grothe, B. (2002). Precise inhibition is essential for microsecond interaural time difference coding. Nature 417, 543-547. doi: 10.1038/417543a

Brewer, G. J., Torricelli, J. R., Evege, E. K., and Price, P. J. (1993). Optimized survival of hippocampal neurons in B27-supplemented neurobasal ${ }^{\mathrm{TM}}$, a new serum-free medium combination. J. Neurosci. Res. 35, 567-576. doi: 10.1002/jnr.490350513

Burger, P. M., Hell, J., Mehl, E., Krasel, C., Lottspeich, F., and Jahn, R. (1991). GABA and glycine in synaptic vesicles: storage and transport characteristics. Neuron 7, 287-293. doi: 10.1016/0896-6273(91)90267-4
«Investissements d'Avenir» (ANR-10-LABX-54 MEMO LIFE, ANR-11-IDEX-0001-02 PSL), the FRM (DEQ 20140329498) and grants from the Association Française contre les Myopathies. KA was supported by a fellowship from the Association Française contre les Myopathies and received support from PMRI Ltd.

\section{ACKNOWLEDGMENTS}

We thank Hanns U. Zeilhofer for providing the GlyT2-EGFP mice and Bruno Gasnier for providing BON:VIAAT cells. We thank Guillaume Dugué and Charly Rousseau for SpAcAn (http://www.spacan.net/) adaptations; and Dan Costa and Rachel O’Connell for statistical advice.

\section{SUPPLEMENTARY MATERIAL}

The Supplementary Material for this article can be found online at: https://www.frontiersin.org/articles/10.3389/fnsyn. 2018.00040/full\#supplementary-material

Burzomato, V., Beato, M., Groot-Kormelink, P. J., Colquhoun, D., and Sivilotti, L. G. (2004). Single-channel behavior of heteromeric $\alpha 1 \beta$ glycine receptors: an attempt to detect a conformational change before the channel opens. J. Neurosci. 24, 10924-10940. doi: 10.1523/JNEUROSCI.342404.2004

Calamai, M., Specht, C. G., Heller, J., Alcor, D., Machado, P., Vannier, C., et al. (2009). Gephyrin oligomerization controls GlyR mobility and synaptic clustering. J. Neurosci. 29, 7639-7648. doi: 10.1523/JNEUROSCI.5711-08.2009

Chéry, N., and de Koninck, Y. (1999). Junctional versus extrajunctional glycine and GABAA receptor- mediated IPSCs in identified lamina I neurons of the adult rat spinal cord. J. Neurosci. 19, 7342-7355. doi: 10.1523/JNEUROSCI.1917-07342.1999

Chéry, N., and de Koninck, Y. (2000). GABAB receptors are the first target of released GABA at lamina I inhibitory synapses in the adult rat spinal cord. J. Neurophysiol. 84, 1006-1011. doi: 10.1152/jn.2000.84.2.1006

Choquet, D., and Triller, A. (2013). The dynamic synapse. Neuron 80, 691-703. doi: 10.1016/j.neuron.2013.10.013

Christensen, H., and Fonnum, F. (1991). The ontogeny of the uptake systems for glycine, GABA and glutamate in synaptic vesicles isolated from rat spinal cordmedulla. Dev. Brain Res. 64, 155-159. doi: 10.1016/0165-3806(91)90219-9

Colqhoun, D., and Hawkes, A. (1995). A Q-Matric Cookbook. New York, NY: Plenum Press.

Coull, J. A., Boudreau, D., Bachand, K., Prescott, S. A., Nault, F., Sík, A., et al. (2003). Trans-synaptic shift in anion gradient in spinal lamina I neurons as a mechanism of neuropathic pain. Nature 424, 938-942. doi: 10.1038/nature01868

Dugué, G. P., Dumoulin, A., Triller, A., and Dieudonné, S. (2005). Targetdependent use of co-released inhibitory transmitters at central synapses. J. Neurosci. 25, 6490-6498. doi: 10.1523/JNEUROSCI.1500-05.2005

Edwards, R. H. (2007). The neurotransmitter cycle and quantal size. Neuron 55, 835-858. doi: 10.1016/j.neuron.2007.09.001

Egashira, Y., Takase, M., Watanabe, S., Ishida, J., Fukamizu, A., Kaneko, R., et al. (2016). Unique $\mathrm{pH}$ dynamics in GABAergic synaptic vesicles illuminates the mechanism and kinetics of GABA loading. Proc. Natl. Acad. Sci. U S A 113 , 10702-10707. doi: 10.1073/pnas.1604527113

Farsi, Z., Preobraschenski, J., van den Bogaart, G., Riedel, D., Jahn, R., and Woehler, A. (2016). Single-vesicle imaging reveals different transport mechanisms between glutamatergic and GABAergic vesicles. Science 351, 981-984. doi: 10.1126/science.aad8142

Fischl, M. J., and Burger, M. R. (2014). Glycinergic transmission modulates GABAergic inhibition in the avian auditory pathway. Front. Neural Circuits 8:19. doi: 10.3389/fncir.2014.00019 
Forti, L., Bossi, M., Bergamaschi, A., Villa, A., and Malgaroli, A. (1997). Loosepatch recordings of single quanta at individual hippocampal synapses. Nature 388, 874-878. doi: 10.1038/42251

Frerking, M., Borges, S., and Wilson, M. (1995). Variation in GABA mini amplitude is the consequence of variation in transmitter concentration. Neuron 15, 885-895. doi: 10.1016/0896-6273(95)90179-5

Fykse, E. M., and Fonnum, F. (1988). Uptake of gamma-aminobutyric acid by a synaptic vesicle fraction isolated from rat brain. J. Neurochem. 50, 1237-1242. doi: 10.1111/j.1471-4159.1988.tb10599.x

Gao, B.-X., Stricker, C., and Ziskind-Conhaim, L. (2001). Transition from GABAergic to glycinergic synaptic transmission in newly formed spinal networks. J. Neurophysiol. 86, 492-502. doi: 10.1152/jn.2001.86.1.492

Gardner, S. M., Trussell, L. O., and Oertel, D. (1999). Time course and permeation of synaptic AMPA receptors in cochlear nuclear neurons correlate with input. J. Neurosci. 19, 8721-8729. doi: 10.1523/JNEUROSCI.19-20-08721.1999

Gasnier, B. (2000). The loading of neurotransmitters into synaptic vesicles. Biochimie 82, 327-337. doi: 10.1016/s0300-9084(00)00221-2

Gomeza, J., Ohno, K., Hülsmann, S., Armsen, W., Eulenburg, V., Richter, D. W., et al. (2003). Deletion of the mouse glycine transporter 2 results in a hyperekplexia phenotype and postnatal lethality. Neuron 40, 797-806. doi: 10.1016/s0896-6273(03)00673-1

Granger, A. J., Wallace, M. L., and Sabatini, B. L. (2017). Multi-transmitter neurons in the mammalian central nervous system. Curr. Opin. Neurobiol. 45, 85-91. doi: 10.1016/j.conb.2017.04.007

Hanus, C., Vannier, C., and Triller, A. (2004). Intracellular association of glycine receptor with gephyrin increases its plasma membrane accumulation rate. J. Neurosci. 24, 1119-1128. doi: 10.1523/JNEUROSCI.4380-03.2004

Hell, J. W., Edelmann, L., Hartinger, J., and Jahn, R. (1991). Functional reconstitution of the gamma-aminobutyric acid transporter from synaptic vesicles using artificial ion gradients. Biochemistry 30, 11795-11800. doi: 10.1021/bi00115a009

Hnasko, T. S., and Edwards, R. H. (2012). Neurotransmitter corelease: mechanism and physiological role. Annu. Rev. Physiol. 74, 225-243. doi: 10.1146/annurevphysiol-020911-153315

Hubbard, J. I., Stenhouse, D., and Eccles, R. M. (1967). Origin of synaptic noise. Science 157, 330-331. doi: 10.1126/science.157.3786.330

Inquimbert, P., Rodeau, J. L., and Schlichter, R. (2007). Differential contribution of GABAergic and glycinergic components to inhibitory synaptic transmission in lamina II and laminae III-IV of the young rat spinal cord. Eur. J. Neurosci. 26, 2940-2949. doi: 10.1111/j.1460-9568.2007.05919.x

Imlach, W. L., Bhola, R. F., Mohammadi, S. A., and Christie, M.-J. (2016). Glycinergic dysfunction in a subpopulation of dorsal horn interneurons in a rat model of neuropathic pain. Sci. Rep. 6:e37104. doi: 10.1038/srep37104

Ishibashi, H., Yamaguchi, J., Nakahata, Y., and Nabekura, J. (2013). Dynamic regulation of glycine-GABA co-transmission at spinal inhibitory synapses by neuronal glutamate transporter. J. Physiol. 591, 3821-3832. doi: 10.1113/jphysiol.2012.250647

Jin, H., Wu, H., Osterhaus, G., Wei, J., Davis, K., Sha, D., et al. (2003). Demonstration of functional coupling between gamma-aminobutyric acid (GABA) synthesis and vesicular GABA transport into synaptic vesicles. Proc. Natl. Acad. Sci. U S A 100, 4293-4298. doi: 10.1073/pnas.0730698100

Jonas, P., Major, G., and Sakmann, B. (1993). Quantal components of unitary EPSCs at the mossy fibre synapse on CA3 pyramidal cells of rat hippocampus. J. Physiol. 472, 615-663.

Jonas, P., Bischofberger, J., and Sandkühler, J. (1998). Corelease of two fast neurotransmitters at a central synapse. Science 281, 419-424. doi: $10.1126 /$ science.281.5375.419

Jones, M. V., and Westbrook, G. L. (1995). Desensitized states prolong GABAA channel responses to brief agonist pulses. Neuron 15, 181-191. doi: 10.1016/0896-6273(95)90075-6

Kakizaki, T., Oriuchi, N., and Yanagawa, Y. (2015). GAD65/GAD67 double knockout mice exhibit intermediate severity in both cleft palate and omphalocele compared with GAD67 knockout and VGAT knockout mice. Neuroscience 288, 86-93. doi: 10.1016/j.neuroscience.2014.12.030

Katsurabayashi, S., Kubota, H., Higashi, H., Akaike, N., and Ito, Y. (2004). Distinct profiles of refilling of inhibitory neurotransmitters into presynaptic terminals projecting to spinal neurones in immature rats. J. Physiol. 560, 469-478. doi: 10.1113/jphysiol.2004.067017
Keller, A. F., Coull, J. A., Chery, N., Poisbeau, P., and De Koninck, Y. (2001). Region-specific developmental specialization of GABA-glycine cosynapses in laminas I-II of the rat spinal dorsal horn. J. Neurosci. 21, 7871-7880. doi: 10.1523/jneurosci.21-20-07871.2001

Kotak, V. C., Korada, S., Schwartz, I. R., and Sanes, D. H. (1998). A developmental shift from GABAergic to glycinergic transmission in the central auditory system. J. Neurosci. 18, 4646-4655. doi: 10.1523/jneurosci.18-1204646.1998

Labrakakis, C., Rudolph, U., and De Koninck, Y. (2014). The heterogeneity in GABAA receptor-mediated IPSC kinetics reflects heterogeneity of subunit composition among inhibitory and excitatory interneurons in spinal lamina II. Front. Cell. Neurosci. 8:424. doi: 10.3389/fncel.2014.00424

Lévi, S., Schweizer, C., Bannai, H., Pascual, O., Charrier, C., and Triller, A. (2008). Homeostatic regulation of synaptic glyr numbers driven by lateral diffusion. Neuron 59, 261-273. doi: 10.1016/j.neuron.2008.05.030

Lu, T., Rubio, M. E., and Trussell, L. O. (2008). Glycinergic transmission shaped by the corelease of GABA in a mammalian auditory synapse. Neuron $57,524-535$. doi: 10.1016/j.neuron.2007.12.010

Maric, H. M., Kasaragod, V. B., Hausrat, T. J., Kneussel, M., Tretter, V., Strømgaard, K., et al. (2014). Molecular basis of the alternative recruitment of GABA(A) versus glycine receptors through gephyrin. Nat. Commun. 5:5767. doi: $10.1038 /$ ncomms6767

Martin, D. L., and Rimvall, K. (1993). Regulation of gamma-aminobutyric acid synthesis in the brain. J. Neurochem. 60, 395-407. doi: 10.1111/j.1471-4159. 1993.tb03165.x

Mathews, G. C., and Diamond, J. S. (2003). Neuronal glutamate uptake contributes to GABA synthesis and inhibitory synaptic strength. J. Neurosci. 23, 2040-2048. doi: 10.1523/jneurosci.23-06-02040.2003

McIntire, S. L., Reimer, R. J., Schuske, K., Edwards, R. H., and Jorgensen, E. M. (1997). Identification and characterization of the vesicular GABA transporter. Nature 389, 870-876. doi: 10.1038/39908

Medelin, M., Rancic, V., Cellot, G., Laishram, J., Veeraraghavan, P., Rossi, C., et al. (2016). Altered development in GABA co-release shapes glycinergic synaptic currents in cultured spinal slices of the SOD1(G93A) mouse model of amyotrophic lateral sclerosis. J. Physiol. 594, 3827-3840. doi: 10.1113/jp 272382

Meye, F. J., Soiza-Reilly, M., Smit, T., Diana, M. A., Schwarz, M. K., and Mameli, M. (2016). Shifted pallidal co-release of GABA and glutamate in habenula drives cocaine withdrawal and relapse. Nat. Neurosci. 19, 1019-1024. doi: $10.1038 / \mathrm{nn} .4334$

Mitchell, E. A., Gentet, L. J., Dempster, J., and Belelli, D. (2007). GABAA and glycine receptor-mediated transmission in rat lamina II neurones: relevance to the analgesic actions of neuroactive steroids. J. Physiol. 583, 1021-1040. doi: 10.1113/jphysiol.2007.134445

Moore, L. A., and Trussell, L. O. (2017). Corelease of inhibitory neurotransmitters in the mouse auditory midbrain. J. Neurosci. 37, 9453-9464. doi: 10.1523/jneurosci.1125-17.2017

Nabekura, J., Katsurabayashi, S., Kakazu, Y., Shibata, S., Matsubara, A., Jinno, S., et al. (2004). Developmental switch from GABA to glycine release in single central synaptic terminals. Nat. Neurosci. 7, 17-23. doi: 10.1038/nn1170

Nerlich, J., Keine, C., Rübsamen, R., Burger, R. M., and Milenkovic, I. (2014). Activity-dependent modulation of inhibitory synaptic kinetics in the cochlear nucleus. Front. Neural Circuits 8:145. doi: 10.3389/fncir.2014.00145

Nusser, Z., Cull-Candy, S., and Farrant, M. (1997). Differences in synaptic GABA(A) receptor number underlie variation in GABA mini amplitude. Neuron 19, 697-709. doi: 10.1016/s0896-6273(00)80382-7

O’Brien, J. A., and Berger, A. J. (1999). Cotransmission of GABA and glycine to brain stem motoneurons. J. Neurophysiol. 82, 1638-1641. doi: 10.1152/jn.1999. 82.3.1638

O’Brien, J. A., Sebe, J. Y., and Berger, A. J. (2004). GABAB modulation of $\mathrm{GABA}_{\mathrm{A}}$ and glycine receptor-mediated synaptic currents in hypoglossal motoneurons. Respir. Physiol. Neurobiol. 141, 35-45. doi: 10.1016/j.resp.2004. 03.009

Overstreet, L. S., and Westbrook, G. L. (2003). Synapse density regulates independence at unitary inhibitory synapses. J. Neurosci. 23, 2618-2626. doi: 10.1523/jneurosci.23-07-02618.2003

Pennacchietti, F., Vascon, S., Nieus, T., Rosillo, C., Das, S., Tyagarajan, S. K., et al. (2017). Nanoscale molecular reorganization of the inhibitory postsynaptic 
density is a determinant of GABAergic synaptic potentiation. J. Neurosci. 37, 1747-1756. doi: 10.1523/jneurosci.0514-16.2016

Rahman, J., Latal, A. T., Besser, S., Hirrlinger, J., and Hülsmann, S. (2013). Mixed miniature postsynaptic currents resulting from co-release of glycine and GABA recorded from glycinergic neurons in the neonatal respiratory network. Eur. J. Neurosci. 37, 1229-1241. doi: 10.1111/ejn.12136

Rizzoli, S. O., and Betz, W. J. (2004). The structural organization of the readily releasable pool of synaptic vesicles. Science 303, 2037-2039. doi: $10.1126 /$ science. 1094682

Ropert, N., Miles, R., and Korn, H. (1990). Characteristics of miniature inhibitory postsynaptic currents in CA1 pyramidal neurones of rat hippocampus. J. Physiol. 428, 707-722. doi: 10.1113/jphysiol.1990.sp018236

Rousseau, F., Aubrey, K. R., and Supplisson, S. (2008). The glycine transporter GlyT2 controls the dynamics of synaptic vesicle refilling in inhibitory spinal cord neurons. J. Neurosci. 28, 9755-9768. doi: 10.1523/jneurosci.0509-08.2008

Rousseau, C. V., Dugué, G. P., Dumoulin, A., Mugnaini, E., Dieudonné, S., and Diana, M. A. (2012). Mixed inhibitory synaptic balance correlates with glutamatergic synaptic phenotype in cerebellar unipolar brush cells. J. Neurosci. 32, 4632-4644. doi: 10.1523/JNEUROSCI.5122-11.2012

Roux, M. J., and Supplisson, S. (2000). Neuronal and glial glycine transporters have different stoichiometries. Neuron 25, 373-383. doi: 10.1016/s08966273(00)80901-0

Russier, M., Kopysova, I. L., Ankri, N., Ferrand, N., and Debanne, D. (2002). GABA and glycine co-release optimizes functional inhibition in rat brainstem motoneurons in vitro. J. Physiol. 541, 123-137. doi: 10.1113/jphysiol.2001. 016063

Sagné, C., El Mestikawy, S., Isambert, M. F., Hamon, M., Henry, J. P., Giros, B., et al. (1997). Cloning of a functional vesicular GABA and glycine transporter by screening of genome databases. FEBS Lett. 417, 177-183. doi: 10.1016/s00145793(97)01279-9

Shabel, S. J., Proulx, C. D., Piriz, J., and Malinow, R. (2014). Mood regulation. GABA/glutamate co-release controls habenula output and is modified by antidepressant treatment. Science 345, 1494-1498. doi: 10.1126/science. 1250469

Strata, P., and Harvey, R. (1999). Dale's principle. Brain Res. Bull. 50, 349-350. doi: $10.1016 /$ S0361-9230(99)00100-8

Südhof, T. C. (2012). The presynaptic active zone. Neuron 75, 11-25. doi: 10.1016/j.neuron.2012.06.012

Takamori, S. (2016). Presynaptic molecular determinants of quantal size. Front. Synaptic Neurosci. 8:2. doi: 10.3389/fnsyn.2016.00002
Takazawa, T., Choudhury, P., Tong, C.-K. K., Conway, C. M., Scherrer, G., Flood, P. D., et al. (2017). Inhibition mediated by glycinergic and GABAergic receptors on excitatory neurons in mouse superficial dorsal horn is location-specific but modified by inflammation. J. Neurosci. 37, 2336-2348. doi: 10.1523/jneurosci.2354-16.2017

Tritsch, N. X., Granger, A. J., and Sabatini, B. L. (2016). Mechanisms and functions of GABA co-release. Nat. Rev. Neurosci. 17, 139-145. doi: 10.1038/nrn.2015.21

Truckenbrodt, S., Viplav, A., Jähne, S., Vogts, A., Denker, A., Wildhagen, H., et al. (2018). Newly produced synaptic vesicle proteins are preferentially used in synaptic transmission. EMBO J. 37:e98044. doi: 10.15252/embj.201798044

Tyagarajan, S. K., and Fritschy, J. M. (2014). Gephyrin: a master regulator of neuronal function? Nat. Rev. Neurosci. 15, 141-156. doi: 10.1038/nrn3670

Vaaga, C. E., Borisovska, M., and Westbrook, G. L. (2014). Dual-transmitter neurons: functional implications of co-release and co-transmission. Curr. Opin. Neurobiol. 29, 25-32. doi: 10.1016/j.conb.2014.04.010

Wang, L., Tu, P., Bonet, L., Aubrey, K. R., and Supplisson, S. (2013). Cytosolic transmitter concentration regulates vesicle cycling at hippocampal GABAergic terminals. Neuron 80, 143-158. doi: 10.1016/j.neuron.2013.07.021

Wojcik, S. M., Katsurabayashi, S., Guillemin, I., Friauf, E., Rosenmund, C., Brose, N., et al. (2006). A shared vesicular carrier allows synaptic corelease of GABA and glycine. Neuron 50, 575-587. doi: 10.1016/j.neuron.2006.04.016

Yamashita, M., Kawaguchi, S. Y., Hori, T., and Takahashi, T. (2018). Vesicular GABA uptake can be rate limiting for recovery of ipscs from synaptic depression. Cell Rep. 22, 3134-3141. doi: 10.1016/j.celrep.2018. 02.080

Zeilhofer, H. U., Studler, B., Arabadzisz, D., Schweizer, C., Ahmadi, S., Layh, B., et al. (2005). Glycinergic neurons expressing enhanced green fluorescent protein in bacterial artificial chromosome transgenic mice. J. Comp. Neurol. 482, 123-141. doi: 10.1002/cne.20349

Conflict of Interest Statement: The authors declare that the research was conducted in the absence of any commercial or financial relationships that could be construed as a potential conflict of interest.

Copyright (๑) 2018 Aubrey and Supplisson. This is an open-access article distributed under the terms of the Creative Commons Attribution License (CC BY). The use, distribution or reproduction in other forums is permitted, provided the original author(s) and the copyright owner(s) are credited and that the original publication in this journal is cited, in accordance with accepted academic practice. No use, distribution or reproduction is permitted which does not comply with these terms. 